\title{
PAULO LEMINSKI E TORQUATO NETO: DOIS "KAMIQUASES"
}

Fabrício Marques de Oliveira

UFMG

\section{REFERENCIAS BBBLIOGRÉFICAS}

CARRATO, José Ferreiro. Igrejo, lluminismo e escolos mineiros coloniais: notos sobre o culturo do decodêncio mineira setecentisto.

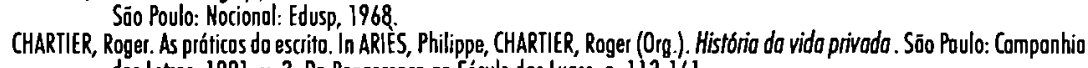
dos Letros, 1991. v. 3: Do Renoscenco oo Século das luzs Do

CURTIUS, Ennest Robert. Literoturo europeio e loode Media latino. 2. ed. Brosilia: MEC: INL, 1979.

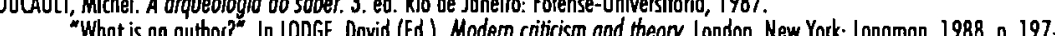
210.

FRIEIRO, Eduordo. O diabo no livroria do cônego : como ero Gonzogo? e outros temas mineiros. 2. ed. rev. e oum. Belo Horizonte: Itotioio; Sóo Poulo: Edusp, 1981.

PROENÇA FllHO, Domício (Org.). A poesia dos inconfidentes: poesio completo de Cláudio Monuel do Costa, Tamós Antônio Gonzogo e Alvarengo Peixoto. Rio de Joneira: Novo Aguilar, 1996

SOUZA, Loura de Mello. Desclossificados do ouro : o pobrezo mineiro no século XVIII. Rio de Joneiro: Grool, 1986.

\section{RESUMO:}

Este ensaio tem por objetivo a comparação entre dois poetas brasileiros contemporâneos, Paulo Leminski e Torquato Neto, no que concerne não somente ao Tropicalismo, mas também à concepção de poesia enquanto invenção.

PALAVRASCHAVE:

Poesia Brasileira Contemporânea, Tropicalismo.

Concomitante ao seu surgimento na cena cultural e artística brasileira em fins dos anos 60, o tropicalismo trouxe consigo um redemoinho em cujo epicentro se desdobraram as mais diversas polêmicas. Estas, no entanto, eram guiadas numa só direção: o imperativo de falar do país. Nesse contexto, algumas perguntas aparecem: que é arcaico? Que é moderno? Qual música é erudita, e qual a popular? Deve-se trabalhar apenas com as raízes nacionais ou incorporar, além disso, as manifestações artísticas extrínsecas? A Tropicália coloca essas questões sob suspeita, relativizando-as e redimensionando-as. Ao lado delas, discute-se também a possibilidade de a canção ser, ao mesmo tempo, crítica e inserção no mercado. Isso porque, como assinala Celso Favaretto, "se por um lado, a atividade artística se realiza inevitavelmente segundo a ordem do mercado, por outro, não deixa de se afirmar como tentativa de transformação da 
sensibilidade, das convenções, dos comportamentos"'. O tropicalismo não só trouxe a reboque um redemoinho, como foi uma "explosão colorida" que submeteu, antropofagicamente, a tradição musical, a ideologia do desenvolvimento e o nacionalismo populista a um processo de desconstrução, como lembra Favaretto. Respirava-se, então, os ares sufocados dos anos de chumbo pós-golpe militar de 64, tempos de forte polarização ideológica.

O movimento tropicalista, do qual Torquato Neto foi um dos nomes fundamentais, teve grande importância na obra poética de Paulo Leminski, um dos mais importantes poetas brasileiros contemporâneos, autor de Caprichos $e$ relaxos (1983), Distraídos venceremos (1987), La vie en close (1991) e $O$ exestranho (1996).

Com a Tropicália, foi possível ver que "o centro da poesia se deslocou do livro para a música popular. (...) Com a geração que produziu Caetano e Chico, viu-se deslocar o pólo da poesia, do suporte livro para o suporte disco"', o que significa que a palavra escrita pode aprender com a palavra falada. E que a contribuição dos grandes mestres da poesia brasileira foi e é grandiosa, mas não é suficiente. É preciso algo mais. Como diz Nelson Ascher,

...quem quer que tenha vivido a idade formativa dos 60 para cá e tenha pretensões poéticas, soube de poesia, antes de mais nada, sob a forma de música popular. Pode-se aprender com Bandeira, Drummond, Cabral, Murilo, mas quem deu a corda foi a MPB, para mais de uma geração, e através dela. Torquato e seus contemporâneos, correligionários, cúmplices. $^{3}$

Em determinados poemas de Leminski, transferidas para o plano da linguagem poética, encontram-se as marcas que vão definir a atividade tropicalista, de acordo com Celso Favaretto: "relação entre fruição estética e crítica social, em que esta se desloca do tema para os processos construtivos"; articulação de "uma nova linguagem da canção a partir da tradição da MPB e dos elementos que a modernização fornecia", elaborando uma síntese de música e poesia, de melodia e texto; na justaposição de elementos diversos da cultura, a obtenção de "uma suma cultural de caráter antropofágico"; "operação desmistificadora, efetuada através da mistura de elementos contraditórios,

\section{FAVARETTO, 1979, p. 97}

2. LEMINSKI, 1994, p.26

3. ASCHER, 1995. p.6. privilegiando o elemento crítico"; "construções paródico-alegóricas (imagens tropicais); "crítica da musicalidade e autocrítica".

Um outro dado que se faz presente na Tropicália (e que levaria o Leminski-tropicalista a afirmar, num texto de Anseios crípticos: "fui dos primeiros, em Curitiba, a usar blusão vermelho e deixar o cabelo crescer"s) é valorizado pela poeta Ana Cristina César, que nela vê " a expressão de uma crise, uma opção estética que inclui um projeto de vida, em que o comportamento passa a ser elemento crítico, subvertendo a ordem mesma do cotidiano". Continua a poeta:

O 'desvio pós-tropicalista' apresenta uma ambiguidade básica: por um lado valoriza-se a marginalidade urbana, a liberação erótica, a experiência das drogas, a atitude festiva, e por outro, verifica-se uma constante atenção a certos referenciais do sistema e da cultura consagrada, como o rigor técnico, a preocupação com a competência na realização de obras, a valorização do bom acabamento dos produtos

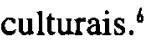

Dentro da Tropicália, movimento em torno do qual se uniram artistas como Caetano Veloso, Gilberto Gil e Tom Zé, um dos nomes fundamentais foi o de Torquato Neto. E talvez este seja, dentro do movimento, o nome que mais se aproxime de Paulo Leminski. Torquato e Leminski foram "kamiquases", cada um a seu modo. Uma primeira aproximação com o autor de Geléia Geral pode ser este breve perfil traçado por Décio Pignatari:

Era um criador-representante da nova sensibilidade dos nãoespecializados. Um poeta da palavra escrita que se converteu à palavra falada (...). Torquato foi o Mário Faustino do Tropicalismo, o Mário tragicamente morto dez anos antes. Ambos, mortos vocacionais.'

Em mais de uma oportunidade, Leminski demonstrou suas afinidades e admirações para com Torquato, como nesses dois depoimentos:

4. FAVARETTO, 1979 , p.8, $11,18,19$ \& 20

5. LEMINSKI, 1986. p.78.

6. CÉSAR, 1993. p.127.

7. PIGNATARI, 1982. 
Torquato é um caso à parte. De longe, a melhor prosa desta geração. Sua prosa supera a de Oswald de Andrade. A agilidade, a exatidão, o teor de novidade em tudo, a eletricidade: não conheço nada melhor que Os últimos dias de Paupéria, que têm que ser para nós os primeiros dias de uma riqueza muito grande. ${ }^{B}$

Existem alguns tipos de prosa brasileira, é a prosa de Torquato, uma prosa elétrica, mas é uma prosa na linguagem. Quer dizer, trata-se de uma prosa opaca como a poesia, uma prosa densa de informação como a poesia. Uma prosa que transcenda assim a mera denotação e atinja o status de objeto de arte.'

Prosa elétrica, encharcada de novidade, densa de informação: textos para jornais, poemas e letras de música reunidos em Os últimos dias de Paupéria, título dado por Waly Salomão. Paupéria sendo uma "região de parcas pecúnias de Pindorama", a expressão do "miserabilismo terceiro-mundista. Pindaíba"10. Os últimos dias, referência direta à "reiterada anunciação da morte pessoal".

Para Torquato, coroas de Leminski:

um dia as fórmulas fracassam

a atração dos corpos cessou

as almas não combinam

esferas se rebelam contra a lei das superfícies

quadrados se abrem

dos eixos

sai a perfeição das coisas feitas nas coxas

abaixo o senso de proporções

pertenço ao número

dos que viveram uma época excessiva"
Outra confluência possível entre os dois poetas diz respeito ao fato de ambos desfrutarem de um gosto por expressões de linguagens populares. Leminski era estudioso e colecionador de provérbios e invenções verbais populares, como lembra Régis Bonvicino, que vê o Catatau como engendrado e articulado a partir do "corriqueiro provérbio"'l2. Já Torquato "era um amante recolhedor das joias do pensamento de pára-choque de caminhão", segundo Waly Salomão ${ }^{13}$.

Torquato flertou com o concretismo, de maneira mais explícita, no poema A matéria o material - 3 estudos de som, para ritmo. Além disso, publicou no espaço interdisciplinar que era a sua coluna Geléia Geral, no jornal Última Hora (1971-1972), entre assuntos que iam do cinema à música, da literatura às artes plásticas, (que traziam, entre outros, e dando conta da diversidade, os nomes de Oswald de Andrade, Glauber Rocha, Rogério Sganzerla, Ângela Maria, Roberto Carlos), traduções de poemas de Li T'Ai Po, Dante e Maiakóvski feitas por Augusto de Campos.

De certa forma, a atuação multimídia de Leminski, principalmente entre meados dos anos 70 até 89 (ano de sua morte), seja como tradutor, seja atuando como agitador cultural, ou mesmo aparecendo em programas televisivos, parece pôr em prática um dos postulados básicos veiculados por Torquato Neto na sua coluna diária, como se depreende dos trechos seguintes:

E agora? Eu não conheço uma resposta melhor do que esta: vamos continuar. E a primeira providência continua sendo a mesma de sempre: conquistar espaço, tomar espaço, ocupar espaço. Inventar os filmes, fornecer argumentos para os senhores historiadores que vão pintar.

O que eu chamo de 'ocupar espaço' está, de certa maneira, naquele Teorema de Pasolini. Ocupar espaço, num limite de tradução, quer dizer tomar o lugar. Não tem nada a ver com subterrânea (num sentido literal), e está mesmo pela superfície, de noite e com muito veneno. (...) Ocupar espaço, criar situações. Ocupa-se um espaço vago como também se ocupa um lugar ocupado: everywhere. ${ }^{14}$

\section{BONVICINO, 19920. p.171}

13. SALOMĀO, 1995. p.13.

14. TOROUATO NETO, 1982. p. 137 e 180, espectivomente.
REVISTA DE ESTUDOS DE IITERATURA

Belo Horizonte, v. 4, p. 135 - 145, out. 96

\footnotetext{
8. LEMINSKI, 1992. p.175.

10. SALOMÄO, 1992.p. 6

11. LEMINSKI, 1992.p. 159
} 
Eram frases imperativas, ordens do dia, numa realidade no "meiotermo desgraçado entre o sufoco político e cotidiano, a destruição do ambiente cultural e as solicitações da contracultura". Um estreitamento do qual a imagem 'ocupar espaço' procurava dar conta, já que também a "sobrevivência era dura e magra"'s.

A proposta de Leminski - para ser poeta é preciso ser mais do que poeta - trava relação, em seu fulcro, com estas palavras de Torquato:

Escute, meu chapa: um poeta não se faz com versos. É o risco, é estar sempre a perigo sem medo, é inventar o perigo e estar sempre recriando dificuldades pelo menos maiores, é destruir a linguagem e explodir com ela. Nada no bolso ou nas mãos. Sabendo: perigoso, divino, maravilhoso. ${ }^{16}$

Era necessário incorporar, existencialmente, a poesia, e nisso vai menos um toque idealista-romântico do que uma constatação melancólica, assim traduzida por Leminski, numa carta a Régis Bonvicino: "fazer poemas não é a coisa mais importante/ mas para quem faz é/ e tem que ser assim"'l7. Wisnick:

Outra confluência entre Leminski e Torquato, notada por José Miguel

Torquato pertence a uma linha de poetas que alcançaram grande fluidez entre a poesia escrita e a poesia cantada. Em sua obra única, a poesia $\mathrm{e}$ a canção se correspondem sem serem separadas por uma fronteira de níveis de densidade. Vinícius anunciou primeiro esse trânsito entre a poesia e a canção, mas nele ainda está marcada a distinção entre as duas. Torquato avança por esse campo aberto, por onde circularão depois poetas como Leminski e Cacaso. ${ }^{18}$

Esse trânsito livre entre poesia falada e escrita tem uma conotação nostálgica, "poesia de volta às origens: no início, poesia era canção. O ser da poesia só se explica, geneticamente, pela sua origem como letra de música,

15. MACHADO, 1992. p.6.

16. TORQUATO NETO, 1982. p.67.

17. LEMINSK, 1992. p.46.

18. WISNICK, 1992. p.4. porque ela estava ligada com a esfera musical"19. Decorre daí uma passagem, na produção poética de Leminski, do valor espaço para o valor tempo. O primeiro se ocupa da plasticidade, da disposição da palavra na página, com a materialidade da palavra impressa na página, enquanto que o segundo se liga ao aspecto musical. Há um determinado momento, em sua poesia, que o interesse se transfere para a cadência da fala, a poesia se torna mais caudalosa. O registro da escrita é dado no tempo, na substância fugaz da voz, na música, no grão da voz barthesiano, como evidencia o seguinte poema:

Escrevia no espaço.

Hoje, grafo no tempo,

na pele, na palma, na pétala,

luz do momento.

Sôo na dúvida que separa

o silêncio de quem grita

do escândalo que cala,

no tempo, distância, praça,

que a pausa, asa, leva,

para ir do percalço ao espasmo. (LVEC, p.18)

São descendentes diretos dessa influência ligada à música e, em especial, ao tropicalismo, versos como esses, nos quais prepondera a melopéia, que Régis Bonvicino viu como sendo "melodias escritas com harmonias sintáticas irreverentes (...) onde o sentido vai se dando pelo encantamento sincopado do som"'l!:

Condenado a ser exato

quem dera poder ser vago

fogo fátuo sobre um lago

ludibriando igualmente

quem voa, quem nada, quem mente,

mosquito, sapo, serpente. (LVEC, p.23)

19. LEMINSK, 1994. p.28.

20. A partii doqui, as citoşōes dos poemas de Leminski serõo identificadas ossim: LVEC (Lo vie en close); DV (Distroídos venceremos) e CR (Caprichos e relaxos).

21. BONVIINO, 1992b. p. 186 . 
Há textos de Leminski que poderiam exemplificar sua filiação à Tropicália, exemplos de tropicalismo tout court, como é o caso de desmontando o frevo (CER, p.16), vocêl que a gente chama (CER p.56), ou mesmo para que leda me leia (DV, p.62) (chamo de textos porque são mais letras de música do que propriamente poemas no sentido estrito). Inclusive, o poeta chega a fazer um convite para que o leitor também musique uma das letras (para que leda me leia), além de abrir assim seu livro de estréia: "Aqui, (...) poemas para dizer, em voz alta. E poemas, letras, lyrics, para cantar. Quais, quais, é com você, parceiro". Mas a melhor amostragem fica sendo Verdura, sendo inclusive gravada posteriormente por Caetano Veloso no LP Outras palavras (1981), e que poderia muito bem ter sido escrita por Torquato:

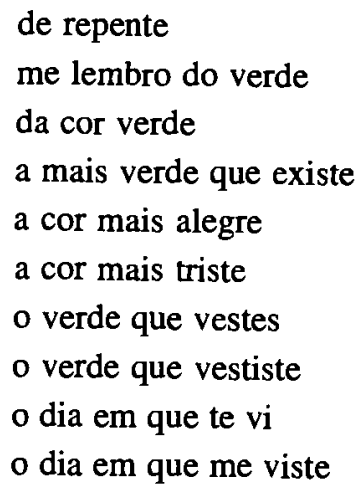

O ambiente inicial do texto (embasado por paralelismos gramaticais, como: o dia em que te vil o dia em que me viste; e eles têm carro/ eles têm grana), a partir de um recorte memorialístico dado meio que por acaso (de repente me lembro do verde), é eminentemente tropicalista, utilizando para isso uma das cores-símbolo do Brasil, em todas as suas nuances e contradições ( $a$ cor mais alegre/ a cor mais triste). Desse modo, o poema atinge um tom quase lisérgico, no qual ressaltam ecos do tropicalismo: superbacana, de Caetano Veloso, e ai de ti, copacabana, de Torquato. Ocorre então uma inversão paródica do nacionalismo, principalmente na segunda estrofe, que funciona como uma espécie de crítica política avant la lettre à emigração de brasileiros em busca de melhores condições de vida, numa progressão desenfreada, principalmente para os Estados Unidos, nos anos que se seguiram à primeira publicação do texto em livro (1981).

\section{Poesia e Invenção}

Os textos de Leminski, assim como os de Torquato, parecem tocados pela necessidade de invenção, do poema como texto autônomo, nova realidade diante da(s) realidade(s). Invenção, aqui, pode ter o sentido dado por Leyla Perrone-Moisés:

'Invenção' é também a criação de uma coisa nova, mas não de modo divino e absoluto. Inventar é usar o engenho humano, é interferir localizadamente no conjunto dos artefatos de que o homem dispõe para tornar sua vida mais rica e mais interessante. Dentro de um sistema de Verdade, invenção tem algo até de pejorativo. Diz-se de uma mentira: isso é uma invenção. Daí haver algo de provocador no uso da palavra invenção para designar o fazer artístico. O escritor que diz 'eu invento' recusa as verdades absolutas e os valores estáveis, ressalta sua habilidade mais do que sua inspiração. (...) Chamada de invenção, a obra de arte $e$ comparável à pólvora ou ao avião. ${ }^{22}$

Portanto, ao identificar um certo aspecto das obras de Leminski e Torquato com o conceito de invenção, procura-se, na verdade, clarificar um procedimento comum aos dois poetas, em oposição à idéia de arte reflexiva. Torquato aproxima, de modo explícito, a linguagem do corpo e o corpo da linguagem, ou seja, o poeta procura dar a ver a correspondência entre ato criador 
(recitar/escrever) e dado existencial, acarretando, no atrito entre eles, "imprevisíveis significados", "informação" e "invenção", como nesse trecho:

Quando eu a recito ou quando eu a escrevo, uma palavra - um mundo poluído - explode comigo e logo os estilhaços desse corpo arrebentado, retalhado em lascas de corte e fogo e morte (como napalm) espalham imprevisíveis significados ao redor de mim: informação. Informação: há palavras que estão nos dicionários e outras que não estão e outras que eu posso inventar, inverter. ${ }^{33}$

O que Leminski pretende, por seu turno, é

CONSTRUIR estruturas, processos e recursos, inovadores, frustrativos às expectativas, aberturas, ciente de que mexer profundamente com os homens é mexer com os próprios fundamentos materiais em que se dá a comunicação. Indústria de base: na própria infra-estrutura sígnica. (...) Função fundadora, construtiva, inovadora, heurística, da consciência. (...) Quem não entende o caráter produtor de consciência, nunca compreenderá a arte de vanguarda. (...) O poema de invenção ou experimental não reflete. Ele é um novo objeto do mundo (um Primeiro). É crítica do mundo, pela linguagem, o que só consegue ser sendo também crítica da linguagem, onde se depositam os valores da cultura, os mitos e os ideologemas vigentes. ${ }^{24}$

Construir, nesse caso, é inventar, passo a passo, palavra por palavra,com a "perfeição das coisas feitas nas coxas", um objeto poético que é a um só tempo e metalingüisticamente, crítica do mundo e da linguagem.

\section{RÉSUMÉ:}

Cet essai a pour but la comparaison entre deux poètes brésiliens contemporaines, Paulo Leminski e Torquato Neto, - qui concerne pas seulement le Tropicalisme, mais aussi la conception de la poésie comme invention. MOISCLCÉS:

\section{Poésie Brésilienne Contemporaine, Tropicalisme.}

REFERÊNCIAS BBBUIOGRÁFICAS

ASCHER, Nelson. Com o letristo, MPB gonho status de poesia. Folho de Sro Poula, Söo Poula, 08. nov. 1992, Mois!.

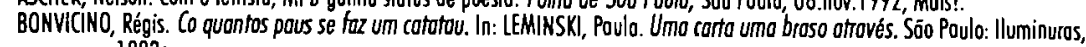
19920

Lo vie en close. In: LEMINSKI, Poulo. Uma carto umo broso atrovés. Söo Poulo: lluminuros, 1992b. CESARR, Ana Cristina. Escritos no Rio. Sóo Poulo: Brosiliense: UFRJ, 1993. FAVARETTO, Celso F. Tropićlio: Alegorio, olegrio. Söo Poulo: Koirós, 1979 LEMINSKL, Poulo. Arseios cripticos. Curitiba: Crior Ediçoes, 1986.

_. Coprichos e reloxos. São Poulo: Brasiliense, 1983,

- Diálogo In: SERIE PARANAENSES. Curitibr.

Lo vie en close. Sóo Poulo: Brosiliense, 1991

- Oexestronho. Sōo Poulo: Alice Ruiz e Aureo Leminski (org.). São Poulo: lluminuros, 1996. Perou carto umo bross otrovés / cortos a Régis Bonvicino (1976-1981). Sõa Poulo: lluminuras, 1992. PERRONE-MOISES, Leylo. Fores do escrivaninho. Sóa Poulo: Componhio dos Letros, 1990. PIGHATARI, Décio. Um depoimento-entrevisto. In: TORQUATO NETO, Os últimos dios de poupério. Sóo Poulo: Mox Limonod, 1982. MACHADO, Dudo. Adolessente somavo o delirio e a críico. Folho de São Poulo, Sõo Poula, 08.nov. 1992, Mois. SALOMAO, Woly. Cove, conem, cuidado com o cóo. Fotha de Sôo Poulo, Söo Paulo, 05. nov.1995. Mais! . Torquato Neto esqueceu os aspos. Folha de São Poulo, Sõo Paulo, 08. nov. 1992, Mois!

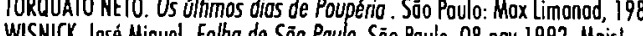
WISNICK, José Miguel. Folho de Sóo Poulo, Söo Poulo, 08.nov.1992, Mais!. 